\title{
Health Economic Impact of First Pass Success: An Asia-Pacific Cost Analysis of the ARISE II Study
}

\author{
Leonard Yeo, ${ }^{\mathrm{a}, \mathrm{b}}$ Osama O. Zaidat, ${ }^{\mathrm{c}}$ Jeffrey L. Saver, ${ }^{\mathrm{d}}$ Heinrich P. Mattle, ${ }^{\mathrm{e}}$ Stephanie Hsiao Yu Lee, ${ }^{\mathrm{f}}$ \\ Emilie Kottenmeier, ${ }^{\mathrm{g}}$ Heather L. Cameron, ${ }^{\mathrm{h}}$ Rana A. Qadeer, ${ }^{\mathrm{h}}$ Tommy Andersson ${ }^{\mathrm{i}, \mathrm{j}}$ \\ ${ }^{a}$ Division of Neurology, National University Health System, Singapore \\ 'Department of Medicine, Yong Loo Lin School of Medicine, National University of Singapore, Singapore \\ 'Department of Neuroscience, Mercy Health St. Vincent Mercy Hospital, Toledo, OH, USA \\ ${ }^{\mathrm{d}}$ Department of Neurology, University of California Los Angeles, Los Angeles, CA, USA \\ 'Department of Neurology, Inselspital, University of Bern, Bern, Switzerland \\ fJohnson \& Johnson Medical Asia Pacific, Singapore \\ ${ }^{9}$ Cerenovus, Johnson \& Johnson, Irvine, CA, USA \\ 'EVERSANA, Burlington, ON, Canada \\ 'Departments of Neuroradiology, Karolinska University Hospital and Clinical Neuroscience, Karolinska Institutet, Stockholm, Sweden \\ jDepartment of Medical Imaging, AZ Groeninge, Kortrijk, Belgium
}

\section{Dear Sir:}

The first pass effect (FPE) is an independent predictor of good functional outcomes (modified Rankin Scale [mRS] 0-2) and is associated with reduced 90-day mortality. ${ }^{1}$ However, the economic impact of FPE has not been evaluated in the Asia-Pacific (APAC) region. This analysis assessed the procedural/hospitalization-related and long-term care economic impact of achieving FPE in patients with acute ischemic stroke in Australia, India, Japan, South Korea, Singapore, and Taiwan.

A detailed description of the methods can be found in Supplementary methods. Briefly, post hoc analyses were conducted using patient-level data from the 227 patients in the Analysis of Revascularization in Ischemic Stroke With EmboTrap (ARISE) II study, a prospective single-arm international multi-center clinical trial investigating the efficacy and safety of the EmboTrap device (Cerenovus, Irvine, CA, USA). ${ }^{2}$ FPE was defined as restoring complete or near complete reperfusion (modified Thrombolysis in Cerebral Infarction [mTICl] 2c-3) in a single pass with the EmboTrap device. The target population comprised patients who achieved $\mathrm{mTICl} 2 \mathrm{c}-3(\mathrm{n}=172)$, stratified into two groups: FPE (mTICl 2c-3 after the first pass) and nonFPE (mTICl 2c-3 after multiple passes). Primary analyses were conducted in two steps. First, clinical and healthcare resource use data from the ARISE II study were evaluated for the FPE and non-FPE groups. Second, cost data from peer-reviewed literature or market research (Supplementary Table 1) were applied to healthcare resource use data from the ARISE II study to assess cost consequences in each group using two time-horizons to accommodate two different perspectives: (1) procedural/hospitalization-related (i.e., length of stay [LOS], standard bed days, intensive care unit [ICU] days, and procedural devices used) assessing costs from the healthcare provider perspective; and (2) long-term care costs based on 90-day mRS (per annum for Australia, Japan, and South Korea; 6 months for India) assessing costs from the payer perspective. All costs were reported as 2020 currencies or 2020 United States dollar (USD) except Singapore (2019 currencies) and were inflated using country-specific inflation indices. Sensitivity analyses, varying key input parameters (i.e., alternative definitions for FPE ["FPE, mTICl 3" and "FPE, mTICl 2b-3"], LOS, healthcare resource costs, and inclusion of costs for mRS 6), were conducted to test the robustness of the results.

Complete or near-complete reperfusion ( $\mathrm{mTICl} 2 \mathrm{c}-3$ ) was observed in $76 \%$ of the patients $(n=172)$ in the ARISE II study. Among patients that achieved $\mathrm{mTICl} 2 \mathrm{c}-3,53 \%(\mathrm{n}=91)$ achieved FPE. Baseline characteristics were balanced between the FPE and non-FPE groups (Supplementary Table 2). Patients in the FPE group had better clinical outcomes (Supplementary Table 3). Furthermore, patients who achieved FPE required a 
single EmboTrap device whereas 35\% of patients in the nonFPE group required additional devices such as other stent retrievers and/or aspiration catheters. Patients in the FPE group had a significantly shorter mean LOS (6.10 days [interquartile range (IQR), 3.00 to 8.00 ] vs. 9.48 days [IQR, 3.00 to 11.00 ], $P<0.01)$ and spent significantly fewer mean number of days in a standard bed (3.05 [IOR, 0.00 to 5.00] vs. 6.13 [IQR, 1.00 to 8.00], $P<0.01)$. The mean number of days spent in the ICU (3.39

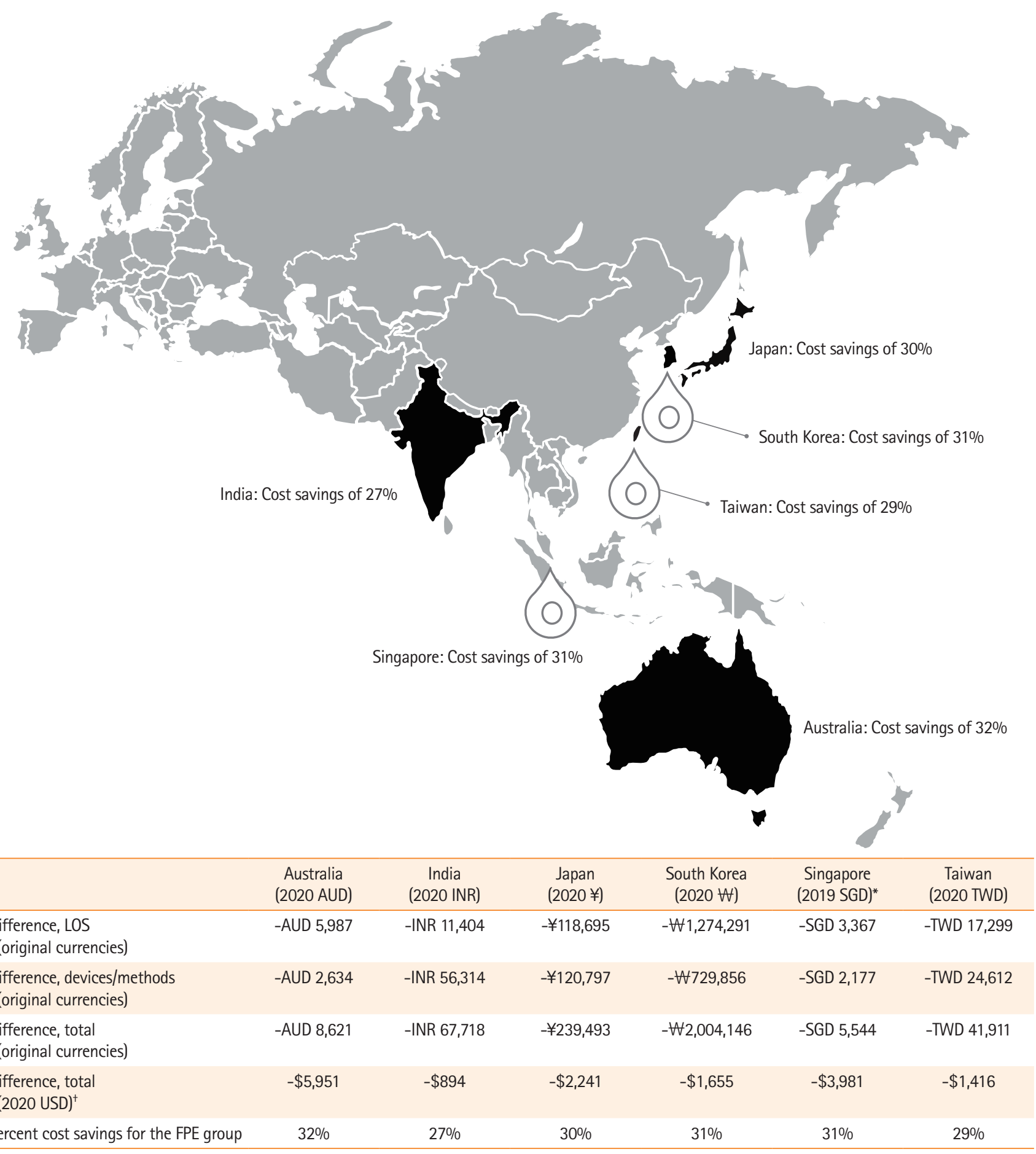

Figure 1. Estimated per-patient procedural and hospitalization-related healthcare use cost savings for the first pass effect (FPE) and non-FPE groups. Negative values represent cost savings for patients in the FPE group as compared with the non-FPE group. Numbers may not sum due to rounding. AUD, Australian dollar; INR, Indian rupee; SGD, Singapore dollar; TWD, Taiwan dollar; LOS, length of stay; USD, United States dollar. *Reported as charges; ${ }^{+}$Reported as 2019 USD for Singapore. Exchange rates reported for June 22, 2020 16:00 Coordinated Universal Time (UTC) were used for all countries. The exchange rates were as follows: 1.00 AUD:0.69 USD; 1.00 INR:0.01 USD; 1.00 JPY:0.01 USD; 1.00 W:0.001 USD; 1.00 SGD:0.72 USD; and 1.00 TWD:0.03 USD. 


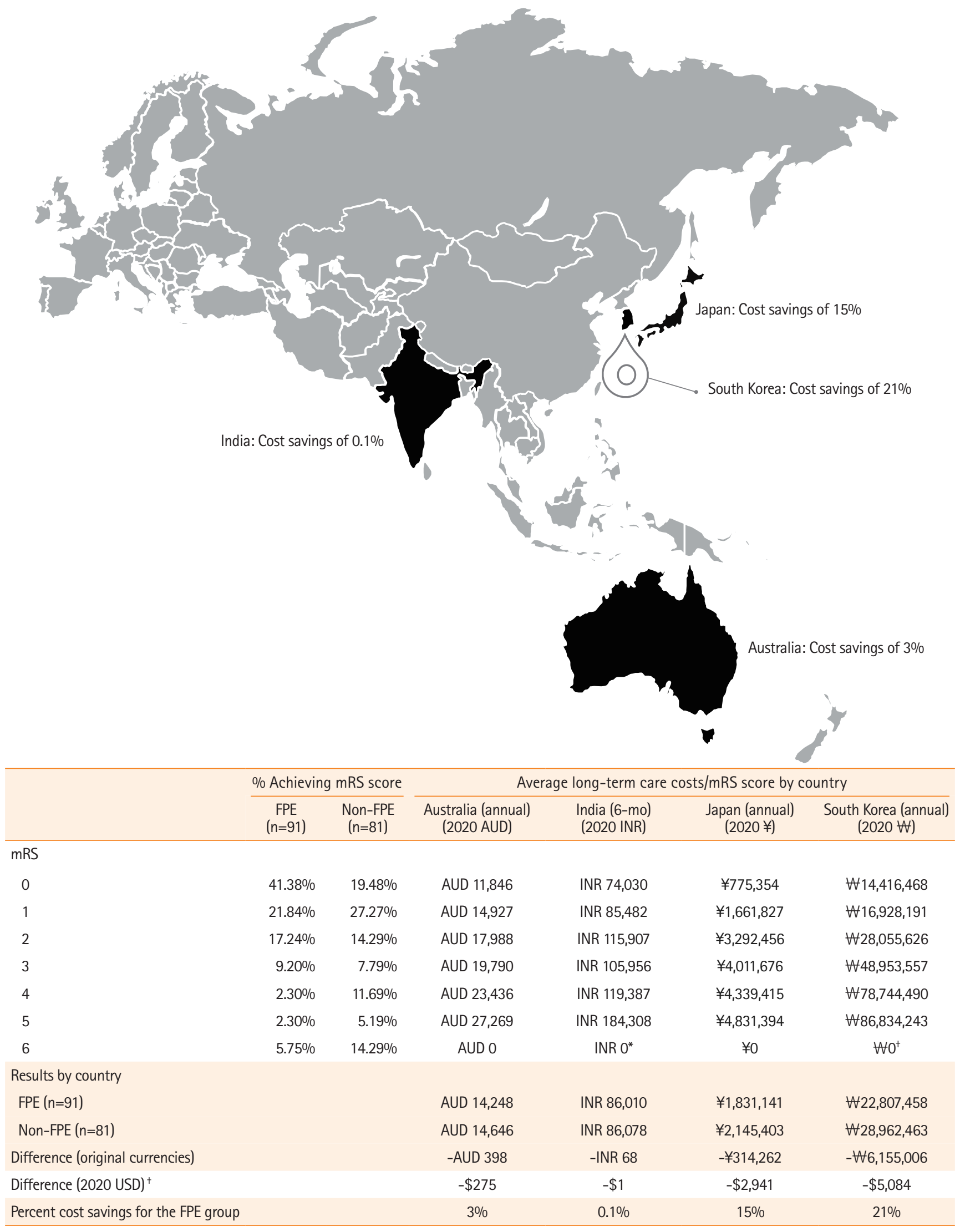

Figure 2. Estimated per-patient long-time care cost savings, based on 90-day modified Rankin Scale (mRS), for the first pass effect (FPE) and non-FPE groups. Negative values represent cost savings for patients in the FPE group as compared with the non-FPE group. Numbers may not sum due to rounding. AUD, Australian dollar; INR, Indian rupee; USD, United States dollar. "Reported for India and South Korea but not used for analyses to ensure consistency with other countries that did not report a cost for death (i.e., mRS 6); ${ }^{\dagger}$ Exchange rates reported for June 22, 2020 16:00 Coordinated Universal Time (UTC) were used for all countries. The exchange rates were as follows: 1.00 AUD:0.69 USD; 1.00 INR:0.01 USD; 1.00 JPY:0.01 USD; and 1.00 W:0.001 USD. 
[IQR, 2.00 to 4.00$]$ vs. 3.58 [IQR, 2.00 to 4.00$], P=0.70$ ) was similar between groups. Achieving FPE led to estimated perpatient procedural/hospitalization-related cost savings in every country studied (8,621 Australian dollar [AUD] or $\$ 5,951$ USD for Australia, 67,718 Indian rupee [INR] or \$894 USD for India, $¥ 239,493$ or $\$ 2,241$ USD for Japan, $\forall 2,004,146$ or $\$ 1,655$ USD for South Korea, 5,544 Singapore dollar [SGD] or \$3,981 USD for Singapore, and 41,911 Taiwan dollar [TWD] or $\$ 1,416$ USD for Taiwan) (Figure 1). Similarly, achieving FPE led to estimated per-patient long-term care cost savings in every country studied (398 AUD or \$275 USD for Australia, 68 INR or \$1 USD for India, $¥ 314,262$ or $\$ 2,941$ USD for Japan, and $\$ 6,155,006$ or $\$ 5,084$ USD for South Korea) (Figure 2). Results from the sensitivity analyses were consistent with the primary analyses; notably, inclusion of costs for mRS 6 resulted in long-term care cost savings of 13,353 INR for India and $\$ 8,359,695$ for South Korea (Supplementary Table 4).

This study demonstrated that achieving FPE led to potential per-patient procedural/hospitalization-related cost savings, which is especially meaningful for healthcare systems that pay hospitals on the basis of diagnosis-related groups or related payment models. These potential cost savings were largely driven by improvements in clinical outcomes; research has shown that increases in mean LOS are directly correlated with mRS evaluated 90 days after a stroke. ${ }^{3}$ The potential long-term care cost savings from improvements in functional outcomes are linked to reduced healthcare resource use and decreased costs for patients surviving stroke. ${ }^{4}$ Our findings are aligned with a cost-effectiveness analysis that showed that achieving expanded Thrombolysis in Cerebral Infarction (eTICl) 3 resulted in more quality-adjusted life years, as well as healthcare and societal cost savings compared with achieving eTICl $2 b$ among patients with large vessel occlusions. ${ }^{5}$

There are several factors related to the treating physician (e.g., training), setting (e.g., available equipment), and patient (e.g., clot composition) that may impact the ability to achieve FPE; however, techniques involving the combined use of stent retrievers and other devices (e.g., intermediate catheters) may improve recanalization rates and the rate of FPE. ${ }^{6,7}$ As such, it may be beneficial to use techniques involving multiple devices immediately rather than beginning with a single device approach and gradually combining additional devices to achieve reperfusion after initial failure.

This study had some limitations. First, healthcare resource use collected from clinical trials may not reflect the real-world setting. It is plausible that costs calculated from ARISE II resource utilization may be different in Asia due to variations in clinical practice or population-specific factors. Although sensi- tivity analyses assessing differences by ethnic groups/regions were considered, such analyses were not feasible due to small sample sizes. Second, the ARISE II study did not report cost data; as such, costs were obtained from peer-reviewed literature or market research, limiting validity. However, this study used the best available estimates, which were validated by clinical experts in interviews.

In conclusion, achieving FPE led to potential procedural/hospitalization-related and long-term care cost savings in the APAC region in addition to clinical benefits. As such, achieving reperfusion with a single pass is a relevant goal for endovascular treatment of acute ischemic stroke with holistic benefits.

\section{Supplementary materials}

Supplementary materials related to this article can be found online at https://doi.org/10.5853/jos.2020.05043.

\section{References}

1. Zaidat 00, Castonguay AC, Linfante I, Gupta R, Martin CO, Holloway WE, et al. First pass effect: a new measure for stroke thrombectomy devices. Stroke 2018;49:660-666.

2. Zaidat 00, Bozorgchami H, Ribó M, Saver JL, Mattle HP, Chapot $R$, et al. Primary results of the multicenter ARISE II study (Analysis of Revascularization in Ischemic Stroke With EmboTrap). Stroke 2018;49:1107-1115.

3. Dawson J, Lees JS, Chang TP, Walters MR, Ali M, Davis SM, et al. Association between disability measures and healthcare costs after initial treatment for acute stroke. Stroke 2007;38: 1893-1898.

4. Lobotesis K, Veltkamp R, Carpenter IH, Claxton LM, Saver JL, Hodgson R. Cost-effectiveness of stent-retriever thrombectomy in combination with IV t-PA compared with IV t-PA alone for acute ischemic stroke in the UK. J Med Econ 2016;19:785-794.

5. Kunz WG, Almekhlafi MA, Menon BK, Saver JL, Hunink MG, Dippel DWJ, et al. Public health and cost benefits of successful reperfusion after thrombectomy for stroke. Stroke 2020; 51:899-907.

6. Maegerlein C, Berndt MT, Mönch S, Kreiser K, Boeckh-Behrens $T$, Lehm $M$, et al. Further development of combined techniques using stent retrievers, aspiration catheters and BGC: The PROTECTPLUS Technique. Clin Neuroradiol 2020; 30:59-65.

7. Delgado Almandoz JE, Kayan Y, Young ML, Fease JL, Scholz $J M$, Milner AM, et al. Comparison of clinical outcomes in patients with acute ischemic strokes treated with mechanical 
thrombectomy using either Solumbra or ADAPT techniques. $J$

Neurointerv Surg 2016;8:1123-1128.
Correspondence: Leonard Yeo

National University Hospital, Kent Ridge Wing, Level 4, 5 Lower Kent Ridge Road, 119074, Singapore

Tel: +65-6779-5555

Fax: +65-6872-4101

E-mail: leonard_II_yeo@nuhs.edu.sg

https://orcid.org/0000-0002-4249-0402

Received: December 17, 2020

Revised: December 17, 2020

Accepted: December 29, 2020

This study was funded by Cerenovus, a subsidiary of Johnson and Johnson.

Leonard Yeo is a consultant for Stryker and See-mode. Leonard Yeo has equity in Cereflo; Osama 0. Zaidat is a consultant for Neuravi, Stryker, Penumbra, and Medtronic; Jeffrey L. Saver is an employee of the University of California, which holds a patent on retriever devices for stroke. The University of California, Regents receives funding for Jeffrey L. Saver's services as a scientific consultant regarding trial design and conduct to Covidien/Medtronic and Stryker. Jeffrey L. Saver serves as a consultant (modest) for Abbott, Medtronic, Stryker, and Neuravi/Cerenovus. Jeffrey L. Saver also has contracted stock options (modest) for Rapid Medical; Heinrich P. Mattle reports personal fees from Covidien/ Medtronic, personal fees from Neuravi/Cerenovus, personal fees from Servier, and personal fees from Bayer outside the submitted work; served on the steering committees of the SWIFT PRIME and ARISE studies; Stephanie Hsiao Yu Lee and Emilie Kottenmeier are employees of Johnson and Johnson; Heather L. Cameron and Rana A. Qadeer are paid consultants for Cerenovus; Tommy Andersson is a consultant for Neuravi/Cerenovus, Anaconda, Amnis Therapeutics, and Rapid Medical; served on the steering committees of the ARISE studies. 


\section{Supplementary methods}

\section{Primary data source}

Post hoc analyses were conducted using patient-level data from the 227 patients in the Analysis of Revascularization in Ischemic Stroke With EmboTrap (ARISE) II study, a prospective single-arm international multi-center clinical trial investigating the efficacy and safety of the EmboTrap device (Cerenovus, Irvine, CA, USA). ${ }^{1}$

\section{Target population}

In accordance with the ARISE II study, ${ }^{1}$ first pass effect (FPE) was defined as complete or near complete reperfusion (modified Thrombolysis in Cerebral Infarction [mTICl] 2c-3) after the first pass of the EmboTrap device; alternative definitions for FPE were explored in sensitivity analyses. The target population comprised of patients who achieved $\mathrm{mTICI} 2 \mathrm{c}-3(n=172)$ and patients who did not achieve $\mathrm{mTICl} 2 \mathrm{c}-3(\mathrm{n}=55)$ were excluded from the primary analyses to avoid potential biases. The target population was then stratified into two groups: FPE group (achieved mTICl 2c-3 after the first pass) and non-FPE group (achieved $\mathrm{mTICI} 2 \mathrm{c}-3$ after multiple passes). The two groups were defined based on the $\mathrm{mTICl}$ score measured after the first pass and the subsequent total number of passes after the first pass did not impact categorization.

\section{Primary analyses}

Primary analyses were conducted in two steps. First, clinical and healthcare resource use data from the ARISE II study (i.e., baseline characteristics, clinical outcomes, and healthcare resource used) were evaluated for the FPE and non-FPE groups. Second, cost data from peer-reviewed literature or market research were applied to data from the ARISE II study to assess cost consequences among the two groups.

\section{Baseline characteristics}

Baseline characteristics (i.e., patient demographics, vascular risk factors, clinical presentation, occlusion location, and procedural factors) were compared between the FPE and non-FPE groups to examine potential bias.

\section{Clinical outcomes}

The clinical outcomes included $\mathrm{mTICl}$ score after each pass and the procedure, 90-day modified Rankin Scale (mRS; categorized into good [mRS 0-2] and excellent [mRS 0-1] functional outcomes), 90-day mortality, occurrence of symptomatic intracranial hemorrhage within 24 hours post-procedure based on the Heidelberg Bleeding Classification, and embolization into new territory assessed at 7-day post-procedure.

\section{Healthcare resource use}

Procedural/hospitalization-related healthcare resources, associated with the initial stroke event, included total length of stay (LOS), days in the intensive care unit, standard bed days, and procedural device use (stent retrievers and aspiration devices).

\section{Economic outcomes}

Cost analyses included comparison of cost consequences between the FPE and non-FPE groups from the perspective of six countries (Australia, India, Japan, South Korea, Singapore, and Taiwan) in the Asia-Pacific (APAC) region. These analyses used two time-horizons and perspectives: (1) procedural/hospitalization-related costs were compared from the healthcare provider perspective and (2) long-term care costs after the initial stroke event were compared from the payer perspective. All costs were reported as 2020 currencies or 2020 United States dollar (USD) except Singapore (reported as 2019 currencies) and were inflated using country specific inflation indices if required. Exchange rates were used to convert original currencies to USD for all countries.

The procedural/hospitalization-related economic impact was assessed in four steps. First, the procedural/hospitalization-related healthcare use (i.e., total LOS and procedural devices used) data were obtained for the FPE and non-FPE groups from the ARISE II study. Second, country-specific costs from a provider perspective were obtained from peer-reviewed literature or market research reports. ${ }^{2-9}$ The LOS costs were based on resources used during the hospitalization period (i.e., direct medical costs such as salaries and wages, medical supplies, pharmaceuticals, examinations, and imaging) (Supplementary Table 1). Third, the country-specific costs were applied to the procedural/hospitalization-related healthcare use data to obtain perpatient procedural/hospitalization-related costs for the FPE and non-FPE groups. Fourth, per-patient incremental differences between the FPE and non-FPE groups were calculated.

Long-term care economic impact, based on the 90-day mRS, was also calculated in four steps. First, the proportions of patients achieving each level of $\mathrm{mRS}$ score (i.e., mRS 0 to 6 ) at 90 days, stratified by FPE status, were obtained from the ARISE II study. Second, country-specific costs for long-term care from a payer perspective, based on 90-day mRS scores, were obtained from the published literature. ${ }^{5,10-12}$ The resources captured in the long-term care costs generally included direct medical costs (e.g., rehabilitation, aged/long-term care facilities, general practice visits, and special consultations); however, the long- 
term care costs for India also included direct non-medical (e.g., relocation expenses, and costs of making changes to one's diet, house, car, or related items) and indirect (e.g., production value lost to society due to absence from work) costs. Additionally, while the long-term care costs for Australia, Japan, and South Korea were on a per annum basis, the costs for India were for 6 months. Notably, in the base case, costs for mRS 6 were excluded from the analyses for India and South Korea to ensure consistency with other countries that did not report costs for death (i.e., mRS 6). Long-term care costs were not found for Singapore and Taiwan. Third, country-specific costs were applied to the proportions of patients achieving each level of mRS score to obtain per-patient long-term care costs for the FPE and non-FPE groups. Fourth, per-patient incremental differences between the FPE and non-FPE groups were calculated.

\section{Sensitivity analyses}

Deterministic sensitivity analyses, varying key input parameters, were conducted to test the robustness of the results. These analyses included two alternative definitions for FPE: (1) "FPE (mTICl 3)," defined as achieving mTICl 3 after the first pass and (2) "FPE (mTICl 2b-3)," defined as achieving mTICl 2b-3 after the first pass. When these alternative definitions were assessed, the target population was modified accordingly (e.g., patients in whom mTICl 2b-3 was not achieved were excluded from the analyses when the definition of FPE was changed to FPE [mTICl 2b-3]). Additional sensitivity analyses included variations in total LOS around its interquartile range (IQR), variations in healthcare resource costs by $20 \%$ (i.e., increased and decreased by 20\%), and inclusion of costs for mRS 6 in long-term care costs for India and South Korea (only countries that reported these costs). Other sensitivity analyses assessing differences by ethnic groups/regions and occlusion locations (i.e., anterior vs. posterior) were considered but were not feasible due to small sample sizes.

\section{Statistical analyses}

Categorical variables were described using the number of observations and relevant proportions, while continuous variables were described using the mean or median and standard deviation (SD) or IQR, respectively. Statistical differences between the FPE and non-FPE groups were determined using t-tests or Wilcoxon rank-sum (Mann-Whitney) tests for continuous data and chi-square or Fisher's exact test for categorical data. Differences between groups were considered statistically significantly different when $P$-values were less than 0.05 . All statistical analyses of the ARISE II data were performed using Stata version 15 (StataCorp., College Station, TX, USA). 
Supplementary Table 1. Sources used to obtain costs for analyses

\begin{tabular}{|c|c|c|c|c|c|}
\hline Study & Country & Currency & Components included in costs & Cost (original currency) & Cost (2020 currency) \\
\hline \multicolumn{6}{|l|}{ LOS cost per day } \\
\hline $\begin{array}{l}\text { Cadilhac et al. } \\
(2019)^{4}\end{array}$ & Australia & 2010 AUD & $\begin{array}{l}\text { Clinical costing data from hospitals } \\
\text { (e.g., salaries and wages, medical supplies, } \\
\text { pharmaceuticals, pathology equipment, imaging, } \\
\text { hotel expenses, and indirect costs such as } \\
\text { administration, research, and training) }\end{array}$ & AUD $1,192.15$ & AUD $1,771.34$ \\
\hline Kwatra et al. $(2013)^{5}$ & India & 2013 INR & $\begin{array}{l}\text { Direct medical costs for inpatient care } \\
\text { (hospitalization expenses including investigations) }\end{array}$ & INR 2,388.15 & INR 3,373.93 \\
\hline $\begin{array}{l}\text { Yoneda et al. } \\
(2005)^{6}\end{array}$ & Japan & $2002 ¥$ & $\begin{array}{l}\text { Direct medical costs for beds, staffs, examinations, } \\
\text { medications including surgical procedures, } \\
\text { rehabilitation, and other minor miscellaneous } \\
\text { expenses such as commissions }\end{array}$ & $¥ 33,075.00$ & $¥ 35,116.98$ \\
\hline Jeong et al. (2017) & South Korea & 2017 W & $\begin{array}{l}\text { Acute care costs for room, neurological/physical } \\
\text { examination, medication/injection, bed-side } \\
\text { rehabilitation, laboratory test, and imaging studies }\end{array}$ & $\# 367,109.20$ & W377,009.06 \\
\hline Chow et al. (2010) & Singapore & $\begin{array}{l}2007- \\
2008 \text { SGD }\end{array}$ & $\begin{array}{l}\text { Direct costs incurred during each hospitalization, } \\
\text { including cost of resources utilized and services } \\
\text { received (i.e., ward charges, radiology investigations, } \\
\text { laboratory investigations, expert medical care, cost } \\
\text { of services rendered such as ward procedures, } \\
\text { emergency services, implant fees and rehabilitation, } \\
\text { medication cost, and miscellaneous) }\end{array}$ & SGD 769.00 & $\begin{array}{l}\text { SGD } 996.11 \\
(2019 \text { SGD) }\end{array}$ \\
\hline Liu et al. $(2016)^{9}$ & Taiwan & 2009 TWD & $\begin{array}{l}\text { Direct medical cost of acute stroke care from the } \\
\text { time of admission to discharge, including the } \\
\text { expense for the personnel, imaging studies, } \\
\text { laboratory examinations, medications, and any } \\
\text { interventional management in the emergency } \\
\text { department, intensive care unit, and neurology ward }\end{array}$ & TWD 4,661.52 & TWD 5,118.04 \\
\hline \multicolumn{6}{|l|}{ Cost per mRS score(s) } \\
\hline Arora et al. $(2018)^{10}$ & Australia & 2016 AUD & $\begin{array}{l}\text { Range of costs, in particular further rehabilitation, } \\
\text { aged-care facilities, general practice visits, and } \\
\text { special consultations }\end{array}$ & $\begin{array}{l}\text { mRS 0: AUD 10,499.00 } \\
\text { mRS 1: AUD 13,230.00 } \\
\text { mRS 2: AUD 15,943.00 } \\
\text { mRS 3: AUD } 17,540.00 \\
\text { mRS 4: AUD 20,772.00 } \\
\text { mRS 5: AUD } 24,169.00\end{array}$ & $\begin{array}{l}\text { mRS 0: AUD } 11,845.68 \\
\text { mRS 1: AUD } 14,926.97 \\
\text { mRS 2: AUD } 17,987.96 \\
\text { mRS 3: AUD } 19,789.80 \\
\text { mRS 4: AUD } 23,436.36 \\
\text { mRS 5: AUD } 27,269.08\end{array}$ \\
\hline Kwatra et al. $(2013)^{5}$ & India & 2013 INR & $\begin{array}{l}\text { Direct medical costs } \\
\text { (i.e., hospitalization, laboratory, radiology and } \\
\text { cardiology-related investigations, drugs, nursing } \\
\text { charges, consultant fees, rehabilitation services, and } \\
\text { interdepartmental consultations), direct nonmedical } \\
\text { costs (i.e., transportation costs to healthcare } \\
\text { providers, relocation expenses, and costs of making } \\
\text { changes to one's diet, house, car, or related items), } \\
\text { and indirect costs (i.e., production value lost to } \\
\text { society due to absence from work, disability and } \\
\text { death) }\end{array}$ & $\begin{array}{l}\text { mRS 0: INR } 52,400.00 \\
\text { mRS 1: INR } 60,506.00 \\
\text { mRS 2: INR } 82,042.00 \\
\text { mRS 3: INR } 74,998.00 \\
\text { mRS 4: INR } 84,505.00 \\
\text { mRS 5: INR } 130,458.00 \\
\text { mRS 6: INR } 110,133.00\end{array}$ & $\begin{array}{l}\text { mRS 0: INR } 74,029.58 \\
\text { mRS 1: INR } 85,481.56 \\
\text { mRS 2: INR } 115,907.15 \\
\text { mRS 3: INR } 105,955.54 \\
\text { mRS 4: INR } 119,386.82 \\
\text { mRS 5: INR } 184,308.22 \\
\text { mRS 6: INR } 155,593.50\end{array}$ \\
\hline $\begin{array}{l}\text { Hattori et al. } \\
(2012)^{11}\end{array}$ & Japan & $2011 ¥$ & $\begin{array}{l}\text { Direct medical costs } \\
\text { (i.e., admission to general hospitals, rehabilitation } \\
\text { clinics, and long-term care institutions) }\end{array}$ & $\begin{array}{l}m R S 0: ~ ¥ 738,432.00 \\
\text { mRS 1: } ¥ 1,582,692.00 \\
\text { mRS 2: } ¥ 3,135,672.00 \\
\text { mRS 3: } ¥ 3,820,644.00 \\
\text { mRS 4: } ¥ 4,132,776.00 \\
\text { mRS 5: } ¥ 4,601,328.00\end{array}$ & $\begin{array}{l}\text { mRS } 0: ¥ 775,353.60 \\
\text { mRS } 1: ¥ 1,661,826.60 \\
\text { mRS 2: } ¥ 3,292,455.60 \\
\text { mRS } 3: ¥ 4,011,676.20 \\
\text { mRS 4: } ¥ 4,339,414.80 \\
\text { mRS } 5: ¥ 4,831,394.40\end{array}$ \\
\hline Kim et al. $(2020)^{12}$ & South Korea & 2015 W & $\begin{array}{l}\text { Four categories of costs: inpatient care, outpatient } \\
\text { care, prescribed medication, and long-term care }\end{array}$ & $\begin{array}{l}\text { mRS 0: } \nVdash 14,037,907 \\
\text { mRS 1: } \nVdash 16,483,675 \\
\text { mRS 2: } \nVdash 27,318,915 \\
\text { mRS 3: } \nVdash 47,668,088 \\
\text { mRS 4: } \nVdash 76,676,743 \\
\text { mRS 5: } \nVdash 84,554,067 \\
\text { mRS 6: } \nVdash 25,142,286\end{array}$ & 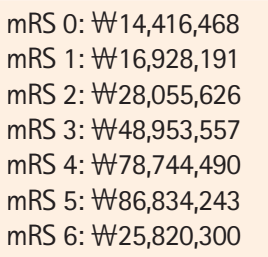 \\
\hline
\end{tabular}


Supplementary Table 2. Baseline characteristics for the FPE and non-FPE groups

\begin{tabular}{|c|c|c|c|}
\hline Variable & $\operatorname{FPE}(n=91)$ & Non-FPE $(n=81)$ & $P^{*}$ \\
\hline \multicolumn{4}{|l|}{ Demographic } \\
\hline Age & $68.4 \pm 11.9$ & $67.7 \pm 14.3$ & 0.70 \\
\hline Male sex & $43(47.3)$ & $33(40.7)$ & 0.39 \\
\hline \multicolumn{4}{|l|}{ Vascular risk factors } \\
\hline Hypertension & $66(72.5)$ & $57(70.4)$ & 0.75 \\
\hline Atrial fibrillation & $32(35.2)$ & $38(46.9)$ & 0.12 \\
\hline Diabetes mellitus & $16(17.6)$ & $17(21.0)$ & 0.57 \\
\hline Dyslipidemia & 38 (41.8) & $37(45.7)$ & 0.61 \\
\hline Smoking & 19 (20.9) & $21(25.9)$ & 0.43 \\
\hline Previous MI/CAD & $23(25.3)$ & $11(13.6)$ & 0.06 \\
\hline Previous stroke & $16(17.6)$ & $13(16.1)$ & 0.79 \\
\hline \multicolumn{4}{|l|}{ Clinical presentation } \\
\hline Baseline NIHSS score & $16(11-19)$ & $16(13-20)$ & 0.40 \\
\hline Baseline systolic BP $\left(\mathrm{mm} \mathrm{Hg}^{+}\right.$ & $144(130-158)$ & 148 (134-158) & 0.31 \\
\hline Baseline diastolic BP $\left(\mathrm{mm} \mathrm{Hg}^{+}\right.$ & $80(70-91)$ & $81(72-93)$ & 0.29 \\
\hline \multicolumn{4}{|l|}{ Occlusion location } \\
\hline Internal carotid artery & $14(15.4)$ & $13(16.1)$ & 0.90 \\
\hline M1 middle cerebral artery & $48(52.8)$ & $46(56.8)$ & 0.60 \\
\hline M2 middle cerebral artery & $22(24.2)$ & $20(24.7)$ & 0.94 \\
\hline Posterior & $7(7.7)$ & $2(2.5)$ & 0.17 \\
\hline \multicolumn{4}{|l|}{ Procedural factors } \\
\hline Time from onset to puncture ( $\mathrm{min}$ ) & $214(161-263)$ & $220(153-270)$ & 0.54 \\
\hline General anesthesia & $33(36.3)$ & 25 (30.9) & 0.46 \\
\hline IV tPA use & $59(64.8)$ & $56(69.1)$ & 0.55 \\
\hline Balloon guide catheter use & $71(78.0)$ & $60(74.1)$ & 0.54 \\
\hline Intermediate catheter use & 20 (22.0) & 41 (50.6) & $<0.01$ \\
\hline
\end{tabular}

Values are presented as mean \pm standard deviation, number (\%), or median (interquartile range).

FPE, first pass effect; MI, myocardial infarction; CAD, coronary artery disease; NIHSS, National Institutes of Health Stroke Scale; BP, blood pressure; IV, intravenous; $\mathrm{CPA}$, tissue plasminogen activator.

${ }^{*} P$-values presented for t-test besides means, Wilcoxon rank sum (Mann-Whitney) test besides medians, and chi-square or Fisher's exact tests besides proportions; ${ }^{+}$Four patients missing data for systolic and diastolic BP. 
Supplementary Table 3. Clinical outcomes for the FPE and non-FPE groups

\begin{tabular}{lccc}
\hline Outcome & FPE $(n=91)$ & Non-FPE $(n=81)$ & \\
\hline 90-Day mRS (categorized into good and excellent functional outcomes) ${ }^{+}$ & & & \\
90-Day mRS, good outcomes (mRS 0-2) & $70(80.46)$ & $47(61.04)$ & $<0.01$ \\
90-Day mRS, excellent outcomes (mRS 0-1) & $55(63.22)$ & $36(46.75)$ & 0.03 \\
90-Day mortality & & $11(13.75)$ & 0.08 \\
sICH within 24 hours & $5(5.68)$ & $4(4.94)$ & 0.42 \\
ENT & $2(2.20)$ & $9(11.11)$ & 0.03 \\
\hline
\end{tabular}

Values are presented as number (\%).

FPE, first pass effect; mRS, modified Rankin Scale; sICH, symptomatic intracranial hemorrhage; ENT, embolization into new territory.

${ }^{*} P$-values presented for chi-square or Fisher's exact tests; ${ }^{\dagger}$ Eight patients missing data for 90 -day mRS; ${ }^{*}$ Four patients missing data for 90 -day mortality.

Supplementary Table 4. Estimated cost differences from sensitivity analyses comparing average per-patient procedural/hospitalization-related and longterm care costs for the FPE and non-FPE groups

\begin{tabular}{|c|c|c|c|c|c|c|}
\hline Country & $\begin{array}{c}\text { Australia } \\
\text { (2020 AUD) }\end{array}$ & $\begin{array}{c}\text { India } \\
\text { (2020 INR) }\end{array}$ & $\begin{array}{c}\text { Japan } \\
(2020 ¥)\end{array}$ & $\begin{array}{c}\text { South Korea } \\
(2020 \text { W) }\end{array}$ & $\begin{array}{l}\text { Singapore } \\
\text { (2019 SGD)* }\end{array}$ & $\begin{array}{c}\text { Taiwan } \\
\text { (2020 TWD) }\end{array}$ \\
\hline \multicolumn{7}{|l|}{$\begin{array}{l}\text { Procedural/hospitalization-related } \\
\text { cost differences }\end{array}$} \\
\hline Base case & AUD 8,621 & INR 67,718 & $¥ 239,493$ & $\forall 2,004,146$ & SGD 5,544 & TWD 41,911 \\
\hline FPE (mTICl 3) & AUD 8,824 & INR 73,091 & $¥ 248,278$ & $\forall 2,055,116$ & SGD 5,725 & TWD 44,203 \\
\hline $\mathrm{FPE}(\mathrm{mTICl} 2 \mathrm{~b}-3)$ & AUD 7,229 & INR 51,509 & $¥ 192,473$ & $W 1,657,149$ & SGD 4,576 & TWD 33,430 \\
\hline LOS (first quartile) $)^{+}$ & AUD 2,634 & INR 56,314 & $¥ 120,797$ & $W 729,856$ & SGD 2,177 & TWD 24,612 \\
\hline LOS (third quartile) ${ }^{+}$ & AUD 7,948 & INR 66,436 & $¥ 226,148$ & $W 1,860,883$ & SGD 5,165 & TWD 39,966 \\
\hline Costs increased by $20 \%$ & AUD 10,345 & INR 81,262 & $¥ 287,391$ & $W 2,404,976$ & SGD 6,652 & TWD 50,293 \\
\hline Costs decreased by $20 \%$ & AUD 6,897 & INR 54,174 & $¥ 191,594$ & $\forall 1,603,317$ & SGD 4,435 & TWD 33,529 \\
\hline \multicolumn{7}{|l|}{ Long-term care cost differences } \\
\hline Base case & AUD 398 & INR 68 & $¥ 314,262$ & $\forall 6,155,006$ & $N A^{+}$ & $N A^{+}$ \\
\hline FPE (mTICl 3) & AUD 361 & INR 500 & $¥ 196,260$ & $\forall 5,277,829$ & $N A^{+}$ & $N A^{+}$ \\
\hline $\mathrm{FPE}(\mathrm{mTICl} 2 b-3)$ & AUD 651 & INR 1,725 & $¥ 400,368$ & $W 8,620,940$ & $N A^{*}$ & $\mathrm{NA}^{+}$ \\
\hline Costs increased by $20 \%$ & AUD 477 & INR 81 & $¥ 377,114$ & $\# 7,386,007$ & $N A^{+}$ & $\mathrm{NA}^{+}$ \\
\hline Costs decreased by $20 \%$ & AUD 318 & INR 54 & $¥ 251,409$ & $\forall 4,924,004$ & $N A^{+}$ & $\mathrm{NA}^{+}$ \\
\hline Costs for mRS 6 included in analyses & $N A^{5}$ & INR 13,353 & $N A^{5}$ & $W 8,359,695$ & $N A^{+}$ & $N A^{+}$ \\
\hline
\end{tabular}

All values represent cost savings for patients in the FPE group as compared with the non-FPE group.

FPE, first pass effect; AUD, Australian dollar; INR, Indian rupee; SGD, Singapore dollar; TWD, Taiwan dollar; NA, not applicable; mTICl, modified Thrombolysis in Cerebral Infarction; LOS, length of stay; mRS, modified Rankin Scale.

*Reported as charges; ${ }^{+}$Variations in LOS did not impact long-term care cost differences; ${ }^{*}$ Long-term care costs, based on 90-day mRS, were not found for Singapore and Taiwan; ${ }^{\circledR}$ Costs for 90-day mRS 6 not reported for Australia and Japan. 


\section{Supplementary references}

1. Zaidat 00, Bozorgchami H, Ribó M, Saver JL, Mattle HP, Chapot $R$, et al. Primary results of the multicenter ARISE II study (Analysis of Revascularization in Ischemic Stroke With EmboTrap). Stroke 2018;49:1107-1115.

2. Iyer S. Neurovascular Devices-Market Insights-Asia Pacific (Supplemental). Decision Resources Group (DRG). https://decisionresourcesgroup.com/report/m360nv0006-medtechneurovascular-devices-market-insights-asia/. 2019. Accessed Deceember 30, 2020.

3. Yadav V. Neurovascular Devices-Market Insights-Japan. Decision Resources Group (DRG). https://decisionresourcesgroup. com/report/m360nv0013-medtech-neurovascular-devicesmarket-insights-japan/. 2020. Accessed Deceember 30, 2020.

4. Cadilhac DA, Dewey HM, Denisenko S, Bladin CF, Meretoja A. Changes in acute hospital costs after employing clinical facilitators to improve stroke care in Victoria, Australia. BMC Health Serv Res 2019;19:41.

5. Kwatra G, Kaur P, Toor G, Badyal DK, Kaur R, Singh $Y$, et al. Cost of stroke from a tertiary center in northwest India. Neurol India 2013;61:627-632.

6. Yoneda Y, Okuda S, Hamada R, Toyota A, Gotoh J, Watanabe $M$, et al. Hospital cost of ischemic stroke and intracerebral hemorrhage in Japanese stroke centers. Health Policy 2005;
73:202-211.

7. Jeong HS, Shin JW, Kwon HJ, Koh HS, Nam HS, Yu HS, et al. Cost benefits of rapid recanalization using intraarterial thrombectomy. Brain Behav 2017;7:e00830.

8. Chow WL, Tin AS, Meyyappan A. Factors influencing costs of inpatient ischaemic stroke care in Singapore. Proc Singap Healthc 2010;19:283-291.

9. Liu $\mathrm{CH}$, Wei $Y C$, Lin JR, Chang $\mathrm{CH}$, Chang TY, Huang $\mathrm{KL}$, et al. Initial blood pressure is associated with stroke severity and is predictive of admission cost and one-year outcome in different stroke subtypes: a SRICHS registry study. BMC Neurol 2016;16:27.

10. Arora N, Makino K, Tilden D, Lobotesis K, Mitchell P, Gillespie J. Cost-effectiveness of mechanical thrombectomy for acute ischemic stroke: an Australian payer perspective. J Med Econ 2018;21:799-809.

11. Hattori N, Hirayama T, Katayama Y. Medical care for chronicphase stroke in Japan. Neurol Med Chir (Tokyo) 2012;52:175180.

12. Kim SE, Lee H, Kim JY, Lee KJ, Kang J, Kim BJ, et al. Threemonth modified Rankin Scale as a determinant of 5-year cumulative costs after ischemic stroke: an analysis of 11,136 patients in Korea. Neurology 2020;94:e978-e991. 